\title{
Evaluation of Clinical Outcomes of Generic versus Reference Ivabradine in Heart Failure Patients
}

\author{
Hadeer Eid Eliwa ${ }^{*}$, Hazem Khorshid ${ }^{b}$, Ahmed Elsherif ${ }^{\mathfrak{c}}$, Ebtissam Darweesh ${ }^{\mathrm{a}}$, Nagwa Ali Sabri ${ }^{\mathrm{d}}$, Naglaa \\ Samir Bazan ${ }^{\mathrm{c}}$ \\ aDepartment of Pharmacy Practice and Clinical Pharmacy, Faculty of Pharmaceutical Sciences and \\ Pharmaceutical Industries, Future University in Egypt, Cairo, Egypt \\ ${ }^{\mathrm{b}}$ Department of Cardiology, Faculty of Medicine, Ain Shams University, Cairo, Egypt \\ ${ }^{\mathrm{c}}$ Department of Critical Care Medicine, Cairo University Hospitals, Cairo-Egypt \\ d Department of Clinical Pharmacy, Faculty of Pharmacy, Ain Shams University, Cairo 11566, Egypt
}

\begin{abstract}
Economic benefits associated with the usage of generic drugs have been suggested to increase patients' adherence to their medications and to improve patients' health outcomes. However, the therapeutic equivalence of certain generic products to their branded counterparts has been questioned. Our study aims to compare the efficacy and safety of generic and branded ivabradine in adult patients with chronic heart failure with reduced ejection fraction $(\leq 40 \%)$ (HFrEF). This was a randomized, open-label, crossover, and two-period comparative study. A total of 32 patients with HFrEF were randomized into two groups. Group A received brand ivabradine® for 12 weeks followed by generic ivabradine for the next 12 weeks. Group B received generic ivabradine for 12 weeks followed by brand ivabradine for the next 12 weeks with no washout period. The efficacy outcomes included resting heart rate (HR), New York Heart Association Functional Classification (NYHA FC), Quality of life (QoL) using Minnesota Living with Heart Failure (MLWHF), and ejection fraction (EF). After taking the drugs for the first 12 weeks, no statistically significant difference was detected in all efficacy outcomes between Group A and Group B. After crossover and taking drugs for a further 12 weeks, similar results were obtained. Only minor side effects, mainly phosphenes were observed in both products. No mortality was demonstrated in both groups. This study showed no statistically significant difference between the generic and brand ivabradine in terms of efficacy and safety. The results suggest that generic ivabradine can be a safe substitute for branded ivabradine for economic reasons.
\end{abstract}

Keywords: Heart Failure; ivabradine, generic; brand; Therapeutic Equivalence.

*Correspondence | Hadeer Eid Eliwa; Department of Pharmacy Practice and Clinical Pharmacy, Faculty of Pharmaceutical Sciences and Pharmaceutical Industries, Future University in Egypt, Cairo, Egypt. Email: hadeir.eid@fue.edu.eg

Citation | Eliwa HE, Khorshid H, Elsherif A, Darweesh E, Sabri NA, Bazan NS, 2020. Evaluation of Clinical outcomes of Generic versus

Reference Ivabradine in Heart Failure Patients. Arch Pharm Sci ASU 4(2): 194-206

DOI: $10.21608 /$ aps.2020.43341.1041

Print ISSN: 2356-8380. Online ISSN: 2356-8399.

Received 22 September 2020. Accepted 28 October 2020.

Copyright: ${ }^{\circledR} 2020$ Eliwa et al. This is an open-access article licensed under a Creative Commons Attribution 4.0 International License (CC BY 4.0), which permits unrestricted use, distribution, and reproduction in any medium, provided the original author(s) and source are credited. Published by: Ain Shams University, Faculty of Pharmacy

\section{INTRODUCTION}

Generic drugs often cost significantly less than their branded counterparts which can enhance patient adherence and decrease health care expenditures [1-4]. This is important for patients with insufficient income and in case of restricted budgets of medical insurance programs [4]. However, generic drugs are considered therapeutically equivalent only based on simple 
bioequivalence studies. On the other hand, branded drugs have to demonstrate their clinical efficacy and safety $[\mathbf{5}, \mathbf{6}]$.

So, whether generic drug products are truly therapeutically identical and interchangeable with their branded counterparts is still controversial and thus can compromise the response and/or safety of patients [7]. Accordingly, and due to the worldwide dynamic expansion of the pharmaceutical market, it is essential to prove the therapeutic equivalence of the generic drugs, which are chemical equivalents of their branded counterparts in terms of active ingredients $[8,9]$.

Ivabradine is a precise inhibitor of the cardiac pacemaker (If) current channel, which modifies pacemaker movement in the sino-atrial node. It gives pure negative chronotropic action without influencing atrioventricular or intraventricular conduction or contractility with no impact on blood pressure $[10,11]$.

Ivabradine was approved by the European Medicines Agency in 2005 and by the United States Food and Drug Administration in 2015 [12]. It is marketed by Servier under the name Procoralan (worldwide) and by Amgen (which acquired United States commercial rights to the drug from Servier) under the name Corlanor. Currently, it is incorporated in the American College of Cardiology/American Heart Association task force 2017 and the 2016 ESC guidelines for the management of heart failure. It is licensed as an additional drug or as an alternative to beta-blockers (if not tolerated) when the resting heart rate (HR) remains $\geq 70$ bpm in patients with chronic heart failure with reduced ejection fraction $(\leq 40 \%)$ (HFrEF) [1315].

This reduction in HR has been associated with improved QOL and better prognosis in patients with HF [16, 17].

However, Ivabradine efficacy in HF patients with diastolic dysfunction still needs extensive evaluation [18].

Ivabradine generics have been introduced into the Egyptian market, with the cheapest licensed under the trade name Bradipect ${ }^{\circledR}$ by October Pharma. According to the first national large scale registry to study heart failure (HF) patients in Egypt, the prescription rate for ivabradine in ambulatory patients with HF was 20.4\% [19]. Although ivabradine generics are estimated to have similar efficacy and tolerability, head-tohead evaluation of generic and reference ivabradine in terms of efficacy and tolerability was never performed.

This study aims to compare the therapeutic equivalence of generic versus brand name ivabradine in adult Egyptian patients with HFrEF.

\section{METHODS}

A randomized, open-label, 2-sequence, 2period crossover study was conducted on 32 Egyptian patients (16 patients in each group) over a period of 24 weeks with no washout period for the ethical reason [20]. Patients were recruited from the outpatient clinic of the Critical Care Medicine Department, Cairo University Hospitals, and the Cardiology outpatient clinic, Ain Shams University Hospitals during the period from October 2015 to December 2017. All HF patients with age $\geq 18$ years, New York Heart Association Functional Classification (NYHA FC) II, III or IV, sinus rhythm, regular resting heart rate $(\mathrm{HR}) \geq 70$ beats $/ \mathrm{min}$, and ejection fraction $(\mathrm{EF}) \leq 40 \%$ were considered for inclusion into the study. Patients with HF with preserved EF (HFpEF), atrial fibrillation or flutter, thyrotoxic heart disease, severe renal impairment defined as serum creatinine $>3 \mathrm{mg} / \mathrm{dl}$, and severe hepatic impairment with signs of liver cell failure were excluded. Besides, patients on nondihydropyridine calcium-channel blockers, class I 
anti-arrhythmic, and/or strong inhibitors of cytochrome P450 3A4 were excluded.

\subsection{Randomization}

Patients were randomized to Group A and Group B (two phases in each group) by choosing from closed envelopes that were previously prepared. Patients in Group A (16 patients) received brand ivabradine (Procoralan $\odot$ ) tablets for 12 weeks followed by generic ivabradine (Bradipect) tablets for another 12 weeks, while patients in Group B (16 patients) received generic ivabradine for 12 weeks followed by brand ivabradine for another 12 weeks.

\subsection{Data Collection}

Demographic and clinical characteristics were assessed at baseline and monthly thereafter, (Table 1). Quality of life was assessed using the Minnesota Living with HF (MLWHF) questionnaire [21]. Also, self-reported side effects and patient adherence to medications were recorded. Echocardiography was performed by the same operator that was blinded to treatment allocated and the previous ECHO findings during the whole study to calculate EF by $2 \mathrm{D}$ modified Simpson's technique. Renal and liver function tests, complete blood count (CBC), NYHA FC, and $\mathrm{EF}$ were assessed at baseline and end of each phase. Medication adherence was evaluated by pill count. Patients in both groups were considered adherent to their medications provided they have taken at least $80 \%$ of the prescribed pills [20].

\subsection{Ethical Approval}

Approval was granted from the committee of ethics of faculty of the pharmacy Ain Shams University (approval number: 238) and Future University in Egypt (approval number: RECFPSPI-4/28). All recruited patients signed informed consent before participation in the study.

\subsection{Primary and Secondary Outcomes}

Primary outcome measures were resting HR, EF, NYHA FC, and QoL at the $12^{\text {th }}$ and $24^{\text {th }}$ week. Also, mortality from cardiovascular disease, adverse events, and the number of hospital admissions for worsening HF were assessed as secondary outcomes.

\subsection{Statistical Analysis}

Statistical analysis was performed using the SPSS software (version 22.0). Chi-square test or Fisher's exact test were used for categorical variables. Independent-samples t-test was used for continuous variables and Mann-Whitney Utest was used if numerical data were not normally distributed. Two-way ANOVA was used to compare the mean difference of change between groups [22] followed by Mauchly's posthoc analysis for pairwise analysis. The significance level was set at $\mathrm{P}<0.05$. By using the PASS 11th release, the minimal sample size for a cross-over design to detect a significant statistical difference between the 2 groups was 14 participants in each group assuming power $=0.80$ and $\alpha=0.05$, Effect Size $=0.5$ [23-26].

\section{RESULTS}

\subsection{Baseline Assessment}

A total of 32 patients were randomized to Group A or Group B (two phases in each group). Ischemic heart disease was the most common etiology of HF (78.1\%). Regarding comorbidities, $53.1 \%$ were hypertensive, $43.8 \%$ were diabetic, and $25 \%$ had dyslipidemia. There was no significant difference between both groups in laboratory parameters, demographic data, cardiac parameters, and NYHA FC. However, the mean EF of group $\mathrm{A}$ was significantly lower than group $\mathrm{B}, \mathrm{p}$-value $=0.02$, (Table 1). Guideline directed medical therapy (ACEIs/ARBs, $\beta$-Blockers, spironolactone, diuretics), patients at $\geq 50 \%$ target dose of $\beta$ blocker, digoxin, statins, antiplatelets, and 
anticoagulants were comparable in both groups. There was no change in brand or doses during the study either in beta-blocker or digoxin after randomization.

Table 1. Baseline demographic and clinical characteristics of patients in the two groups

\begin{tabular}{|c|c|c|c|}
\hline Parameter & Group A (N=16) & Group B $(\mathrm{N}=16)$ & P-Value \\
\hline \multicolumn{4}{|l|}{ Demographic characteristics } \\
\hline \multicolumn{4}{|l|}{ Age(years) } \\
\hline$\geq 55$ year $\mathrm{n}(\%)$ & $3(18.8)$ & $7(43.8)$ & $0.12^{\text {(a) }}$ \\
\hline Gender (male) n (\%) & $15(93.8)$ & $15(93.8)$ & $1.0^{(\mathrm{a})}$ \\
\hline Current Smoking n (\%) & $2(12.5)$ & $6(37.5)$ & $0.18^{\text {(a) }}$ \\
\hline $\mathrm{BMI}($ mean $\pm \mathrm{SD}, \mathrm{Kg} / \mathrm{m} 2)$ & $28.28 \pm 4.89$ & $27.66 \pm 4.94$ & $0.72^{(\mathrm{b})}$ \\
\hline \multicolumn{4}{|l|}{ Cardiac Parameters } \\
\hline Heart Rate by ECG $($ mean $\pm \mathrm{SD}$, bpm) & $90.13 \pm 7.11$ & $94.25 \pm 12.71$ & $0.26^{(\mathrm{b})}$ \\
\hline $\mathrm{SBP}($ mean $\pm \mathrm{SD}, \mathrm{mm} \mathrm{Hg})$ & $113.13 \pm 19.91$ & $120.63 \pm 13.40$ & $0.22^{(\mathrm{b})}$ \\
\hline $\mathrm{DBP}($ mean $\pm \mathrm{SD}, \mathrm{mm} \mathrm{Hg}))$ & $71.56 \pm 14.57$ & $77.5 \pm 10.65$ & $0.20^{(\mathrm{b})}$ \\
\hline \multicolumn{4}{|l|}{$\operatorname{LVEF}(\%)$} \\
\hline$\leq 35 \mathrm{n}(\%)$ & $15(93.8)$ & $10(62.5)$ & $0.026 *(\mathrm{a})$ \\
\hline $\operatorname{LVEF}(\%)$ & $27.44 \pm 4.59$ & $32.0 \pm 5.96$ & $0.02 *(\mathrm{~b})$ \\
\hline \multicolumn{4}{|l|}{ NYHA Classifications } \\
\hline Class II n (\%) & $6(37.5)$ & $1(6.3)$ & $0.07^{\text {(a) }}$ \\
\hline Class III n (\%) & $9(56.3)$ & $12(75.0)$ & \\
\hline Class IV n (\%) & $1(6.3)$ & $3(18.8)$ & \\
\hline QOL (MLWHF score) (me an \pm SD) & $31.63 \pm 15.89$ & $35.69 \pm 17.64$ & $0.62^{(\mathrm{c})}$ \\
\hline \multicolumn{4}{|l|}{ HF Etiology } \\
\hline Ischemic HF n (\%) & $11(68.8)$ & $14(87.5)$ & $0.19^{\text {(a) }}$ \\
\hline
\end{tabular}

Group A: started with brand ivabradine (Procoralan®) for 12 weeks followed by generic ivabradine (Bradipect) for another 12 weeks without washout period.

Group B: started with generic ivabradine (Bradipect) for 12 weeks followed by brand ivabradine (Procoralan $\left.{ }^{\circledR}\right)$ for another 12 weeks without washout period.

* Statistically Significant.

a) Fisher exact, ${ }^{\text {b) }}$ Independent-samples t-test, ${ }^{\text {c) }}$ Mann-Whitney U-test and ${ }^{\text {d) }}$ Chi-square test. BMI, body mass index; SBP, systolic blood pressure; DBP, diastolic blood pressure; LVEF, Lift ventricular ejection fraction; NYHA, New York heart association, QOL, quality of life; MLWHF, Minnesota live with heart failure; HF, heart failure. 


\subsection{Primary Outcomes}

\subsubsection{HR}

All patients received at least $80 \%$ of their drugs during the study period.

At the end of phase 1 (12 $2^{\text {th }}$ week), a comparable reduction in HR occurred in the two groups, P-value=0.64. However, at the end of phase $2\left(24^{\text {th }}\right.$ week $)$, no significant deviations were noticed from data detected at the end of phase 1 in the two groups, $\mathrm{P}$-value $=0.69$, The interaction of time*treatment was not significant $(\mathrm{P}$-value $=0.28),($ Fig. 1)

\subsubsection{EF}

At the start of phase 1, the mean baseline of EF was significantly less in group A compared to group B. However, at the end of phase 1, the mean EF increased from $27.44 \pm 4.59$ to $33.38 \pm 5.62$ with an improvement of $5.94 \pm 3.07$ and mean \% change of $22.19 \pm 11.13$ in group A versus $32 \pm 5.96$ to $39.31 \pm 8.95$ with an improvement of $7.31 \pm 5.82$ and mean $\%$ change of $23.14 \pm 17.72$ in group $\mathrm{B}, \mathrm{P}=0.98$ and 0.78 respectively. At the end of phase 2, when patients were crossed over to generic drug, there was a further increase from $33.38 \pm 5.62$ to 37.75 \pm 5.12 with an improvement of $4.38 \pm 4.58$ and mean \% change $14.57 \pm 15.44$ in group A versus $39.31 \pm 8.95$ to $41.19 \pm 7.97$ with an improvement of $1.88 \pm 2.39$ and \% change of $5.72 \pm 7.45$ in group $\mathrm{B}$ when patients were crossed over to brand drug, $\mathrm{P}=0.13$ and 0.12 respectively. The interaction of time treatment was not significant $(\mathrm{P}$-value $=0.33)$. Fig. 2 shows the percentage of patients with $\mathrm{LVEF} \leq 35 \%$ in the two groups, the improvement in $\mathrm{EF}$ was comparable during phase 1 and phase 2 within groups, P-value $=0.29$ and 1.0, respectively (Fig. 2).

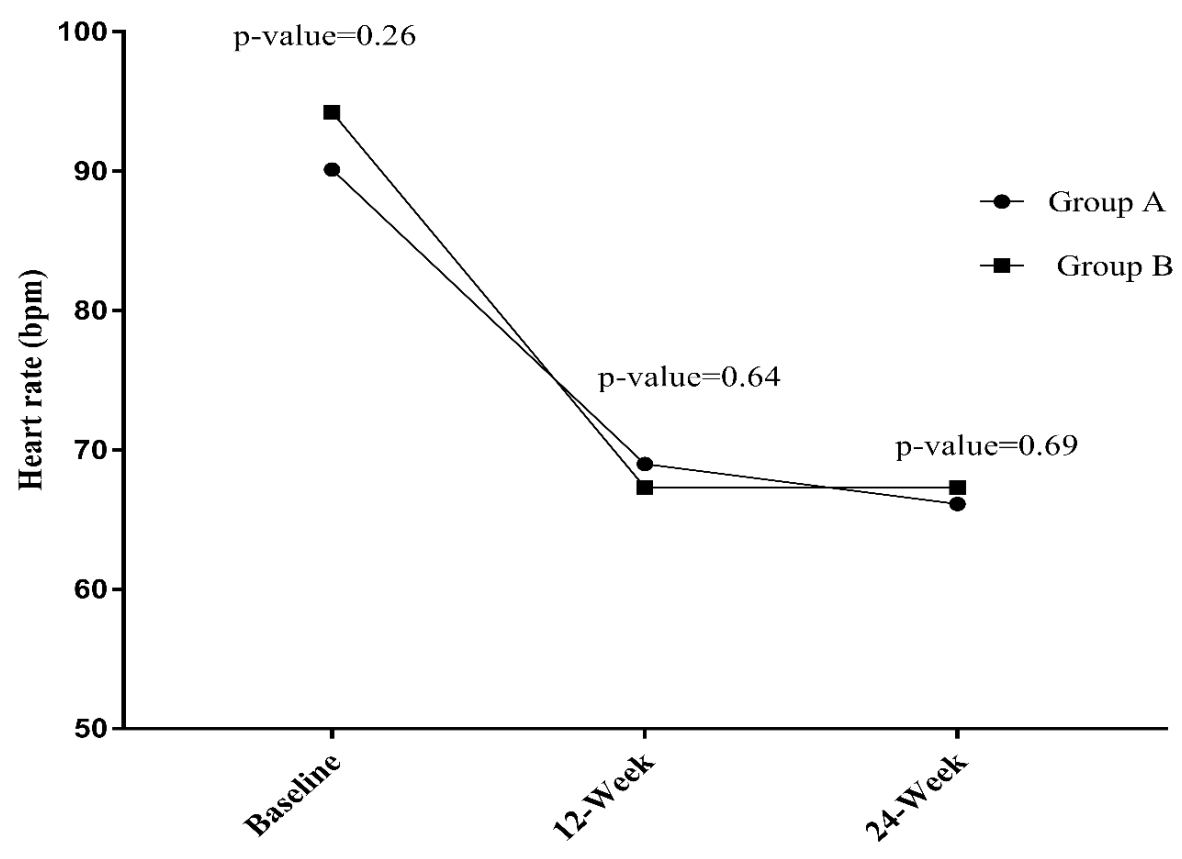

Fig. 1. Mean resting HR during the study period in Group A (16 patients started with the brand ivabradine followed by generic ivabradine and Group B (16 patients started with generic ivabradine followed by branded ivabradine 


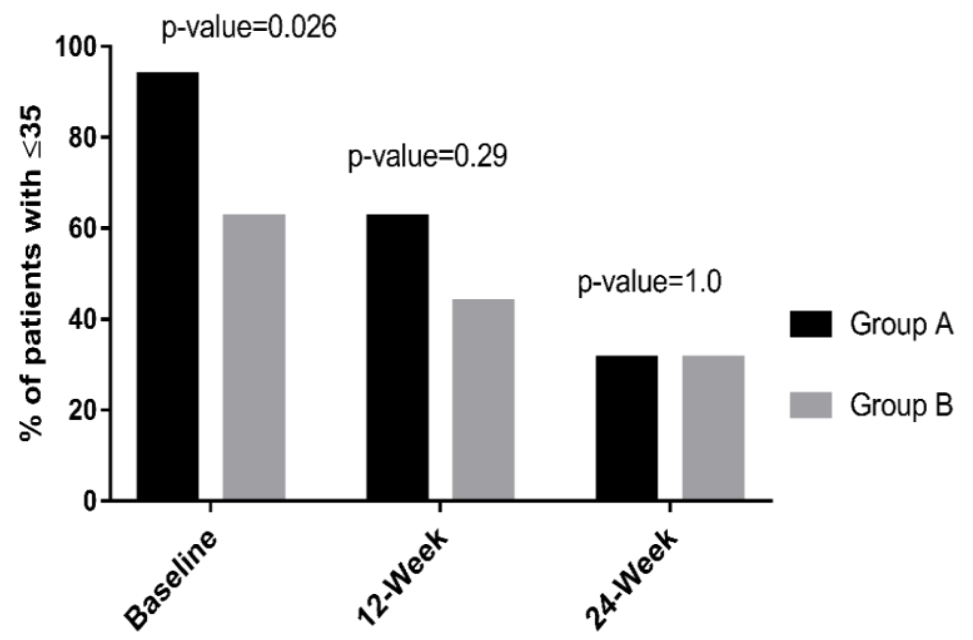

Fig. 2. Percentage of patients with $E F \leq 35$ during the study period in Group A (16 patients started with the brand ivabradine followed by generic ivabradine) and Group B (16 patients started with generic ivabradine followed by brand ivabradine)

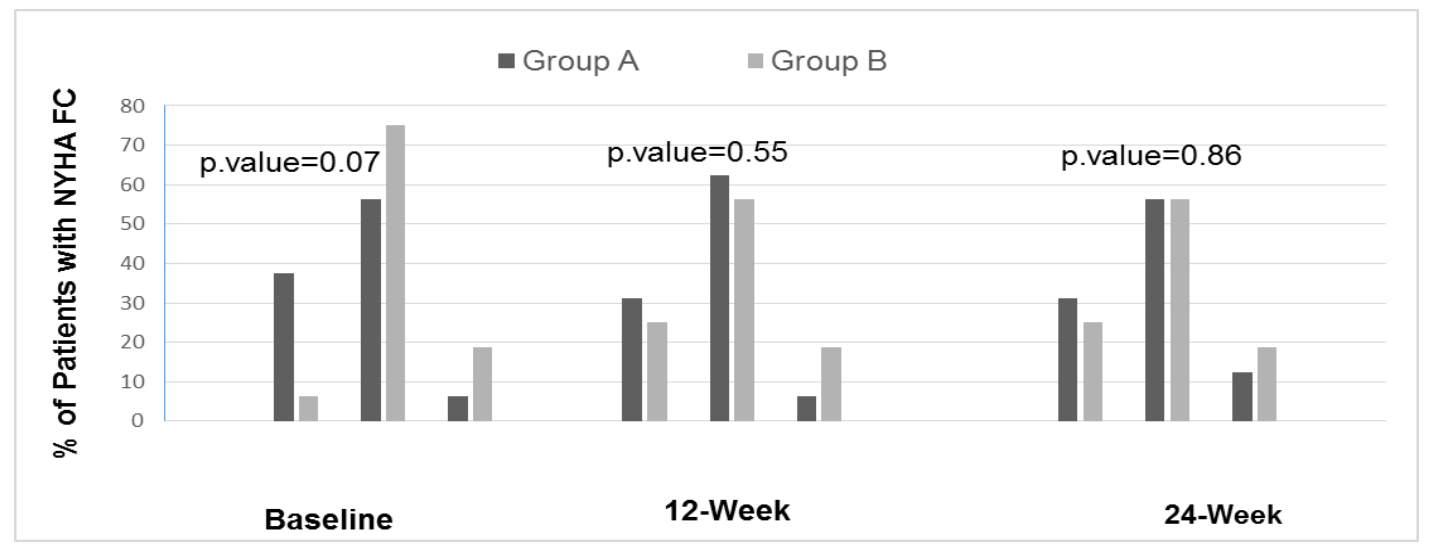

Fig. 3. Proportion of patients in different NYHA classes during the study period in Group A (16 patients started with the brand ivabradine followed by generic ivabradine and Group B (16 patients started with generic ivabradine followed by brand ivabradine)

\subsubsection{NYHA FC}

Fig. 3 shows the NYHA FC classes at baseline, week 12, and week 24. The improvement in NYHA FC was similar in both groups at week $12(87.5 \%$ in group A versus $93.8 \%$ in group B) with no further improvement at week 24 (Fig 3).

\subsubsection{QOL}

At the end of phase 1, the mean value of the QOL improved at the end of phase 1 with no further significant change at the end of phase 2 . Also, the actual QOL improvement was $12 \pm 15.23$ with a mean $\%$ change of $36.71 \pm 30.22$ in group A versus $-12.81 \pm 9.19$ and mean $\%$ change of $37.66 \pm 23.48$ in group B, P-value $=0.29$, and 0.51 , respectively. At the end of phase 2, there was no further improvement and percent change in QOL between the two groups (P- 
value $=0.55)$. The interaction of time*treatment was not significant $(\mathrm{P}$-value $=0.85)$.

\subsection{Secondary Outcomes}

\subsubsection{Adverse events and Cost saving}

At the end of both phases, two patients were hospitalized for worsening $\mathrm{HF}$ in group $\mathrm{A}$, and none in group B. Bradycardia (i.e. HR $<50 \mathrm{bpm}$ ) occurred in two patients in group A. In addition, visual side effects (Phosphenes) occurred in one patient in each group. There was no mortality during the whole study period. The total cost of the brand product was 2331.80 USD, whereas, the total cost of the generic product was 1469.27 USD. If the only generic product was used, the cost-saving would have been 862.53 USD (26.95 USD/patient), which reflects almost $40 \%$ saving. (Table. 2).

Table 2. Cost saving of using generic ivabradine versus brand ivabradine

\begin{tabular}{cccccccc}
\hline Name & $\begin{array}{c}\text { Dose in } \\
\text { mg }\end{array}$ & $\begin{array}{c}\text { Price/b } \\
\text { ox in } \\
\text { USD }\end{array}$ & $\begin{array}{c}\text { No.of } \\
\text { boxes } \\
/ \mathbf{3} \text { months } \\
\text { /patient }\end{array}$ & $\begin{array}{c}\text { No.of } \\
\text { patients } \\
\text { /32 patients }\end{array}$ & $\begin{array}{c}\text { Price of total } \\
\text { boxes } \\
\text { /3 months } \\
\text { /total patients in } \\
\text { USD }\end{array}$ & $\begin{array}{c}\text { Total } \\
\text { Price in } \\
\text { USD }\end{array}$ & $\begin{array}{c}\text { Cost Saving if } \\
\text { generic was } \\
\text { used } \\
\text { /3 months in } \\
\text { USD }\end{array}$ \\
\hline Procoralan & 5 & 12.14 & 6 & 18 & 1311.64 & 2331.80 & 862.53 \\
& 7.5 & 12.14 & 6 & 14 & 1020.16 & & \\
Bradipect & 5 & 7.44 & 6 & 18 & 803.04 & 1469.27 & \\
& 7.5 & 7.93 & 6 & 14 & 666.23 & & \\
\hline
\end{tabular}

\section{DISCUSSION}

The most important reason for the benefits and widespread use of generic drugs is to reduce health care costs. However, the therapeutic equivalence of generics to branded drugs is assumed based on bioequivalence studies only. In addition, a different toxic effect may exist when brand and generic drugs are compared. Accordingly, debatable results occurred when evaluating the equivalence of both generic and brand drugs in terms of clinical outcomes in different medical specialties [27-29]. The most common studies evaluating the therapeutic equivalence of generic drugs versus their branded counterparts involved cardiac drugs $[28,30,31]$, chemotherapeutic drugs, $[7,32-34]$ antiepileptics [35], and bisphosphonates [20]. However, no studies to date evaluated the therapeutic equivalence of generic ivabradine versus brand ivabradine.

In this study, we reported the outcome of a randomized crossover study, which compared the clinical efficacy and safety of locally manufactured generic ivabradine (Bradipect) tablets with that of the original product $\left(\right.$ Procoralan ${ }^{\circledR}$ ) tablets on 32 Egyptian patients with HFrEF. Criteria for evaluation of efficacy and safety of ivabradine were based on the criteria used in the large trials evaluating Ivabradine [36-38]. Ivabradine in $\mathrm{HFrEF}$ has 
been evaluated in two essential placebocontrolled studies: SHIFT [37] and BEAUTIFUL [36] the primary endpoint was a composite of cardiovascular death, admission to hospital for acute myocardial infarction, and admission to hospital for new-onset or worsening $\mathrm{HF}$. Moreover, HR, EF, NYHA FC, and quality of life were assessed. In addition, a prospective, non-interventional, open-label, multi-center study INTENSIFY [38] was conducted which focused on the effect of ivabradine on HR, EF, NYHA FC, and quality of life. Accordingly, in the present study, the primary efficacy outcomes of branded ivabradine were compared to its generic counterpart in terms of resting HR, EF, NYHA FC, and QoL monthly, at $12^{\text {th }}$ week and up to 24 weeks of treatment. The study showed that both generic and branded ivabradine were therapeutically equivalent in patients with $\mathrm{HFrEF}$ concerning HR, EF, NYHA FC, and QOL. In addition, both groups showed a similar toxicity profile. In-group A, the resting HR was reduced by $21.1 \pm 15.2 \mathrm{bpm}$ at end of 3 months $(90.13 \pm 7.11 \mathrm{bpm}$ to $68.25 \pm 9.54 \mathrm{bpm}$ after 1 month and to $69 \pm 11.41 \mathrm{bpm}$ after 3 months versus $27.12 \pm 20.6 \mathrm{bpm} \quad(94.25 \pm 12.71 \mathrm{bpm}$ to70.63 \pm 10.16 bpm after 1 month and $67.31 \pm 8.68 \mathrm{bpm}$ after 3 months) in-group B. This is following a study conducted in Egypt to investigate the efficacy of ivabradine in idiopathic dilated cardiomyopathy (ICM) patients with chronic HF [39]. The baseline HR was reduced from $96 \pm 15$ to 72 with a mean reduction of $24 \pm 13$ at 3 months. However, the magnitude of this reduction was slightly higher than that observed in the INTENSIFY study $(85 \pm 11.8 \mathrm{bpm}$ at baseline to $72 \pm 9.9 \mathrm{bpm}$ after 1 month and $67 \pm 8.9 \mathrm{bpm}$ after 4 months, with $18 \pm 12.3 \mathrm{bpm}$, mean reduction). In addition, the latter study reported that the HR reduction was greater in patients with higher baseline HR. This observation might explain the reason behind the relatively higher reduction in HR in our study and the latter Egyptian study where the mean baseline HR in both studies was $\geq 90 \mathrm{bpm}$. Similarly, in the present study, reduction in HR was slightly higher compared to SHIFT [37] (79.7 bpm to $64 \mathrm{bpm}$ after 1 month) and BEAUTIFUL [36] (79.1 bpm to $65 \mathrm{bpm}$ after 1 month) studies.

Besides, HR was reduced by $8.3 \pm 9.7 \mathrm{bpm}$ (71.5 \pm 10 to $63.2 \pm 9.9 \mathrm{bpm}$ after 3 months of the study period) in the ivabradine group in the BEAUTIFUL Echo sub-study which aimed to assess the effect of HR decrease by ivabradine on left ventricular size [40] Also, a randomized open blinded endpoint study to assess the effect of HR reduction with carvedilol, ivabradine and their combination on exercise capacity in HF patients receiving a maximal dose of ACEIs [41], reported similar results $(76.3 \pm 12.8 \mathrm{bpm}$ to $58.1 \pm 5.4 \mathrm{bpm})$. All latter studies with a lower reduction in HR compared to the present study recorded lower baseline resting HR. Accordingly, this adds evidence to the observations of the INTENSIFY study which reported that patients with higher baseline HR experiences higher reductions in HR.

In the present study, the percentage of patients improved after 3 months of treatment in both groups based on NYHA FC (87.5\% in group A versus $93.8 \%$ in group $B$ with no significant difference). Also, the percentage of patients with NYHA FC I and II increased from $37.5 \%$ to $93.8 \%$ in group A versus $6.3 \%$ to $81.3 \%$ in group B. It is worth mentioning that none of our patients were classified as NYHA FC I at baseline, however, by end of the study $28 \%$ were NYHA FC I. This improvement in NYHA FC was higher than that observed in the SHIFT study (28\%). Also, in the INTENSIFY study, NYHA I and II increased from $9.6 \%$ and $51.1 \%$ to $24.0 \%$ and $60.5 \%$ respectively after 4 months of treatment. This difference from our results may be attributed to the higher percentage of NYHA 
FC III, IV and lower percent of NYHA FC II at baseline compared to both SHIFT and INTENSIFY study. Also, the Egyptian study conducted in ICM patients with HF recorded an improvement in NYHA FC by $12 \%$ only after 3 months of ivabradine [39]. Oppositely, most of our patients had HF due to IHD (78\%) and only (22\%) had DCM.

The percentage of patients with LVEF $\leq 35 \%$ in our study in both groups A and B declined from $93.8 \%$ to $62.5 \%$ and from $62.5 \%$ to $43.8 \%$, respectively after 3 months. In the INTESFIY study, LVEF $\leq 35 \%$ at baseline declined from $26.6 \%$ to $17.4 \%$ after 4 months. This better improvement may be due to the higher percentage of patients with LVEF $\leq 35 \%$ at baseline. This is further supported by our study results which showed that there was an improvement in the mean change value of LVEF for both groups A and B by $5.94 \% \pm 3.07$ and $7.31 \% \pm 5.82$ after 3 months. This is following the Egyptian study which recorded an improvement in LVEF in the ivabradine group by mean change $6.2 \% \pm 8.3$ (31.7\% to $36.8 \%)$ after 3 months. Moreover, Ceconi et al. study conducted to assess the effect of ivabradine on LV size, function and the cardiac biomarker observed an improvement in LVEF in the ivabradine group by mean change $2 \pm 7.02 \%(36.6 \pm 8.7$ to $38.8 \pm 8.5)$ after 3 months [40].

By using the MLWHF score, there was an improvement in the QOL by $12 \pm 15.23$ and $12.81 \pm 9.19 \quad(31.63 \pm 15.8$ to $19.6 \pm 14.7$ and $35.68 \pm 17.63$ to $22.9 \pm 15.1$ ) for both groups A and B respectively. Similarly, Mansour et al. showed a mean improvement in the QOL using the MLWHF score by $12.3 \pm 3.3$. However, the INTENSIFY assessed the QOL using the EQ-5D score index. The mean value of the QOL EQ-5D sum score index was $0.64 \pm 0.28$ at baseline and had improved to $0.79 \pm 0.21$ after 4 months.

A meta-analysis on generic versus brand- name drugs used in cardiovascular diseases was published in 2016. The latter study showed that spending generic as an alternative to brand-name cardiovascular drugs does not indicate a loss in either efficacy or safety [31]. However, there were major limitations to their meta-analysis. First, $50 \%$ of the studies evaluated were bioequivalence trials, had a short follow-up period, low study power due to small sample size and most of the study populations were healthy volunteers. Second, in most studies, either the generic manufacturer sponsored the study, or the source of funding was not reported, thus the results might be subjected to sponsorship bias. Those limitations are similar to a meta-analysis conducted in 2008 to evaluate the therapeutic equivalence of generic and brand-name drugs used in cardiovascular disease [27]. The latter study concluded that although there is no proven evidence to support the superiority of brandname drugs to their generic counterparts, a significant number of articles counsel against interchanging between generic and branded drugs [27].

Briefly, studies comparing therapeutic equivalence of branded drugs versus their generics have limitations and show conflicting results. However, the present study conducted several measures to overcome some of those limitations. First, the study was conducted in a sufficient period of 6 months. Second, HF patients comprised the study population, not healthy volunteers. Third, a crossover design and suitable sample size with suitable power $(80 \%)$ were used. Also, there was no sponsorship bias or any type of conflict of interest.

A limitation to this study was the open-label study design. Additionally, EF was significantly lower at baseline in the group of patients who started with the brand drug compared to the group who started with a generic drug. However, actual improvement and percent change were 
used to evaluate the outcome of EF to overcome this limitation. Moreover, there was no washout period for ethical reasons. Further studies with a larger sample size are required to confirm study results.

\section{Conclusion}

This study showed no statistically significant difference between the generic and brand-name ivabradine in terms of efficacy and safety. Based on our results, we propose that generic ivabradine can be a safe substitute for branded ivabradine for economic reasons. Further studies with a larger sample size are required to confirm study results.

\section{Declarations}

All authors declared that no relevant affiliations or financial association with any corporation or individual with a commercial interest in or financial conflict with the subject matter or resources reviewed in the manuscript.

\section{Ethics approval and consent to participate}

The study protocol was reviewed and approved by the committee of ethics of faculty of the pharmacy Ain Shams University (approval number: 238) and Future University in Egypt (approval number: REC-FPSPI-4/28). All recruited patients signed informed consent before participation in the study.

\section{Consent to publish}

The authors have all approved the final manuscript and decided on the publishing of the submitted work in the APS journal.

\section{Availability of data and materials}

All data generated or analyzed during this study are included in this published article in the main manuscript.

\section{Competing interests}

The authors have all declared that no competing interests exist

\section{Funding Statement}

This analysis was funded by Future University in Egypt, Cairo, Egypt.

\section{Acknowledgment}

The authors would like to thank the Future University in Egypt.

\section{Authors' contributions}

The manuscript was drafted by Hadeer Eid Eliwa, reviewed by Naglaa S.Bazan and all authors reviewed and approved the final manuscript.

\section{List of abbreviations}

HFrEF, Heart Failure with Reduced Ejection Fraction; HR, Heart Rate; NYHA FC, New York Heart Association Functional Classification; QoL, Quality of life; MLWHF, Minnesota Living with Heart Failure; EF, Ejection fraction; HF, Heart Failure; HFpEF, Heart Failure with Preserved Ejection Fraction; ESC, European Society of Cardiology; ACEi, AngiotensinConverting Enzyme Inhibitors; ARBs, Angiotensin Receptor Blockers; BP, Blood Pressure; ECG, Electro Cardio Gram; CBC, Complete Blood Count; ECHO, Echocardiography; SHIFT, The Systolic Heart failure treatment with the $\left(\mathrm{I}_{f}\right)$ inhibitor ivabradine Trial; BEAUTIFUL, Morbidity-mortality evaluation of the $\left(\mathrm{I}_{f}\right)$-inhibitors ivabradine in patients with CAD and left ventricular dysfunction; INTENSIFY, PractIcal daily effectiveNess and TolEraNce of ivabradine in chronic SystolIc heart Failure in Germany; DCM, Dilated cardiomyopathy; IHD, Ischemic Heart Disease; LVEF, left Ventricular Ejection Fraction;

\section{REFERENCES}

1. Kesselheim AS, Fischer MA, Avorn J. Extensions of intellectual property rights and delayed adoption 
of generic drugs: effects on Medicaid spending. Health Aff. 2006;25:1637-47. doi:https://doi.org/10.1377/hlthaff.25.6.1637.

2. Shrank WH, Hoang T, Ettner SL, Glassman PA, Nair K, DeLapp D, et al. The implications of choice: prescribing generic or preferred pharmaceuticals improves medication adherence for chronic conditions. Arch Intern Med. 2006;166:332-7.

doi:https://doi:10.1001/archinte.166.3.332.

3. Goldman DP, Joyce GF, Zheng Y. Prescription drug cost sharing: associations with medication and medical utilization and spending and health. Jama. 2007;298:61-9.

doi:https://doi:10.1001/jama.298.1.61.

4. Cornes P. The economic pressures for biosimilar drug use in cancer medicine. Target Oncol. 2012;7:57-67. doi:https://doi.org/10.1007/s10269011-2017-9.

5. Zore M, Harris A, Tobe LA, Siesky B, Januleviciene I, Behzadi $J$ et al. Generic medications in ophthalmology. Br J Ophthalmol. 2013;97:253-7. doi:http://dx.doi.org/10.1136/bjophthalmol-2012302245 .

6. Malvankar-Mehta MS, Feng L, Hutnik CM. North American cost analysis of brand name versus generic drugs for the treatment of glaucoma. Clinicoecon Outcomes Res. 2019;11:789-98. doi:https://doi.org/10.2147/CEOR.S156558.

7. Ochi N, Yamane H, Hotta K, Fujii H, Isozaki H, Honda $\mathrm{Y}$ et al. Cisplatin-induced hyponatremia in malignancy: comparison between brand-name and generic formulation. Drug Des Devel Ther. 2014;8:2401-8.

doi:https://doi.org/10.2147/DDDT.S71419.

8. Sambu N, Radhakrishnan A, Curzon N. A randomized crossover study comparing the antiplatelet effect of plavix versus generic clopidogrel. J Cardiovasc Pharmacol. 2012;60:495501.

doi:https://doi.org/10.1097/FJC.0b013e31826f36bc

9. Desai RJ, Sarpatwari A, Dejene S, Khan NF, Lii J,
Rogers JR et al. Comparative effectiveness of generic and brand-name medication use: A database study of US health insurance claims. PLoS medicine. 2019;16(3):e1002763. doi:https://doi.org/10.1371/journal.pmed.1002763.

10. Ordu S, Yildiz BS, Alihanoglu YI, Ozsoy A, Tosun M, Evrengul $\mathrm{H}$ et al. Effects of ivabradine therapy on heart failure biomarkers. Cardiol J. 2015;22:501-9.

doi:https://doi.org/10.5603/CJ.a2015.0012.

11. Gammone M, Riccioni G, D’Orazio N. Ivabradine: a new frontier in the treatment of stable coronary artery disease and chronic heart failure. Clin Ter. 2020;171(5):449-53. doi:https://doi.org/10.7417/CT.2020.2256.

12. Corlanor(ivabradine tablets)prescribing information., Thousand Oaks, California: Amgen. Apr 2015. Available at: http://pi.amgen.com/united_states/corlanor/corlano r_pi.pdf. Accessed April 24, 2015.

13. Ponikowski P, Voors AA, Anker SD, Bueno H, Cleland JG, Coats AJ et al. 2016 ESC Guidelines for the diagnosis and treatment of acute and chronic heart failure: The Task Force for the diagnosis and treatment of acute and chronic heart failure of the European Society of Cardiology (ESC). Developed with the special contribution of the Heart Failure Association (HFA) of the ESC. Eur J Heart Fail. 2016;18:891-975. doi:https://doi.org/10.1002/ejhf.592.

14. Yancy CW, Jessup M, Bozkurt B, Butler J, Casey DE, Colvin MM et al. 2017 ACC/AHA/HFSA focused update of the 2013 ACCF/AHA guideline for the management of heart failure: a report of the American College of Cardiology/American Heart Association Task Force on Clinical Practice Guidelines and the Heart Failure Society of America. J Am Coll Cardiol 2017;70:776-803. doi:h t t p : / / d . d o i . or g/10.1016/j .ja c c. 2017.04 .025 .

15. Haboub M, Arous S, Benouna E, Drighil A, Azzouzi L, Habbal R. Symptoms, and quality of life improvement in heart failure patients with reduced LVEF taking ivabradine. Arch Cardiovasc Dis Suppl. 2020;12:51. 
doi:https://doi.org/10.1016/j.acvdsp.2019.09.110.

16. Bocchi EA, Salemi VMC. Ivabradine for treatment of heart failure. Expert Opinion on Drug Safety. 2019;18(5):393-402. doi:10.1080/14740338.2019.1612873.

17. Bouabdallaoui N, O'Meara E, Bernier V, Komajda M, Swedberg K, Tavazzi L et al. Beneficial effects of ivabradine in patients with heart failure, low ejection fraction, and heart rate above $77 \mathrm{bpm}$. ESC heart failure. 2019. doi:https://doi.org/10.1002/ehf2.12513

18. Eid H, Darweesh E, Sabri NA. Ivabradine in Chronic Heart Failure. Arch Pharm Sci ASU. 2020;4:36-46.

doi:https://doi.org/10.21608/APS.2020.2001.1023.

19. Hassanein M, Abdelhamid M, Ibrahim B, Elshazly A, Aboleineen MW, Sobhy $\mathrm{H}$ et al. Clinical characteristics and management of hospitalized and ambulatory patients with heart failure-results from ESC heart failure long-term registryEgyptian cohort. ESC heart failure. 2015;2:159-67. doi:https://doi.org/10.1002/ehf2.12046.

20. van den Bergh JP, Bouts ME, van der Veer E, van der Velde RY, Janssen MJ, Geusens PP et al. Comparing tolerability and efficacy of generic versus brand alendronate: a randomized clinical study in postmenopausal women with a recent fracture. PLoS One. 2013;8:e78153 doi: 10.1371/journal.pone.0078153. doi:doi: 10.1371/journal.pone.0078153.

21. Rector TS, Cohn JN. Assessment of patient outcome with the Minnesota Living with Heart Failure questionnaire: reliability and validity during a randomized, double-blind, placebocontrolled trial of pimobendan. Am Heart J. 1992;124:1017-25. doi:https://doi.org/10.1016/0002-8703(92)90986-6.

22. Mills EJ, Chan A-W, Wu P, Vail A, Guyatt GH, Altman DG. Design, analysis, and presentation of crossover trials. Trials. 2009;10:27. doi:https://doi.org/10.1186/1745-6215-10-27.

23. Chow S, Shao J, Wang H. Marcel Dekker; New York: 2003. Sample Size Calculations in Clinical
Research.41-73.

24. Julious SA. Sample sizes for clinical trials with normal data. Statistics in medicine. 2004;23(12):1921-86. doi: https://doi.org/10.1002/sim.1783.

25. Senn SS. Cross-over trials in clinical research. John Wiley \& Sons; 2002.

26. Hintze J. PASS 11. NCSS, LLC. Kaysville, Utah, USA. 2011.

27. Kesselheim AS, Misono AS, Lee JL, Stedman MR, Brookhart MA, Choudhry NK et al. Clinical equivalence of generic and brand-name drugs used in cardiovascular disease: a systematic review and meta-analysis. Jama. 2008;300:2514-26. doi:https://doi.org/10.1001/jama.2008.758.

28. Dentali F, Donadini MP, Clark N, Crowther MA, Garcia D, Hylek E et al. Brand name versus generic warfarin: a systematic review of the literature. Pharmacotherapy. 2011;31:386-93. doi: https://doi.org/10.1592/phco.31.4.386.

29. Caldeira D, Fernandes RM, Costa J, David C, Sampaio C, Ferreira JJ. Branded versus generic clopidogrel in cardiovascular diseases: a systematic review. J Cardiovasc Pharmacol. 2013;61:277-82.

doi:https://doi.org/10.1097/FJC.0b013e31827e5c6 0 .

30. Komosa A, Siller-Matula J, Kowal J, Lesiak M, Siniawski A, Mączyński $M$ et al. Comparison of the antiplatelet effect of two clopidogrel bisulfate formulations: plavix and generic-Egitromb. Platelets. 2015;26:43-7. doi:https://doi.org/10.3109/09537104.2013.877581

31. Manzoli L, Flacco ME, Boccia S, D’Andrea E, Panic N, Marzuillo C et al. Generic versus brandname drugs used in cardiovascular diseases. Eur J Epidemiol. 2016;31:351-68. doi:https://doi.org/10.1007/s10654-015-0104-8.

32. Sekine I, Kubota K, Tamura Y, Asahina $\mathrm{H}$, Yamada K, Horinouchi $\mathrm{H}$ et al. Innovator and generic cisplatin formulations: comparison of renal toxicity. Cancer Sci. 2011;102:162-5. 
doi:https://doi.org/10.1111/j.1349-

7006.2010.01764.x.

33. Oike T, Ohno T, Noda S-e, Sato H, Tamaki T, Kiyohara $\mathrm{H}$ et al. Comparison of hematological toxicities between innovator and generic cisplatin formulations in cervical cancer patients treated with concurrent chemoradiotherapy. J Radiat Res Appl Sci 2012;54:474-8. doi:https://doi.org/10.1093/jrr/rrs121.

34. Niho S, Yamanaka T, Umemura S, Matsumoto $S$, Yoh K, Goto $\mathrm{K}$ et al. Renal toxicity caused by brand-name versus generic cisplatin: a comparative analysis. Jpn J Clin Oncol. 2013;43:390-5. doi:https://doi.org/10.1093/jjco/hyt020.

35. Kesselheim AS, Stedman MR, Bubrick EJ, Gagne JJ, Misono AS, Lee JL et al. Seizure outcomes following the use of generic versus brand-name antiepileptic drugs: A Systemic Review and MetaAnalysis. Drugs. 2010;70:605-21. doi:https://doi.org/10.2165/10898530-000000000-

00000 .

36. Fox K, Ford I, Steg PG, Tendera M, Ferrari R, Investigators B. Ivabradine for patients with stable coronary artery disease and left-ventricular systolic dysfunction (BEAUTIFUL): a randomized, double-blind, placebo-controlled trial. Lancet. 2008;372:807-16.

doi:https://doi.org/10.1016/S0140-6736(08)611708.

37. Swedberg K, Komajda M, Böhm M, Borer JS, Ford I, Dubost-Brama A et al. Ivabradine and outcomes in chronic heart failure (SHIFT): a randomized placebo-controlled study. Lancet. 2010;376:875-85.

doi:https://doi.org/10.1016/S0140-6736(10)611981.

38. Zugck C, Martinka P, Stöckl G. Ivabradine treatment in a chronic heart failure patient cohort: symptom reduction and improvement in the quality of life in clinical practice. Adv Ther. 2014;31:96174. doi:https://doi.org/10.1007/s12325-014-01473.

39. Mansour S, Youssef A, Rayan M, Saleh MA. Efficacy of ivabradine in idiopathic dilated cardiomyopathy patients with chronic heart failure. Egypt Heart J. 2011;63(2):79-85. doi:https://doi.org/10.1016/j.ehj.2011.09.001.

40. Ceconi C, Freedman S, Tardif J, Hildebrandt P, McDonagh T, Gueret $\mathrm{P}$ et al. Effect of the heart rate reduction by ivabradine on left ventricular remodeling in the echocardiographic substudy of BEAUTIFUL. Int J Cardiol. 2011;146(3):408-14. doi:https://doi.org/10.1016/j.ijcard.2010.10.125.

41. Volterrani M, Price G, Caminiti G, Vitale C, D'Isa S, Filardi PP et al. Effect of Carvedilol, Ivabradine or their combination on exercise capacity in patients with Heart Failure (the CARVIVA HF trial). Int J Cardiol. 2011;151(2):218-24. doi:https://doi.org/10.1016/j.ijcard.2011.06.098. 